\title{
Diagnosis of Causes of Concrete Deterioration in the MLP-7A Parking Garage
}

Paul E. Stutzman

James R. Clifton

June 1994

Building and Fire Research Laboratory

National Institute of Standards and Technology

Gaithersburg, MD 20899

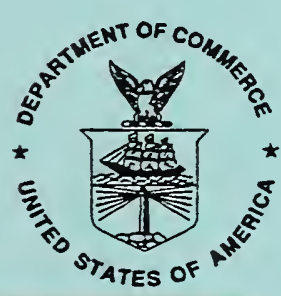

QC

100

.456

N0.5492

1994

Ronald H. Brown, Secretary

Technology Administration

Mary L. Good, Under Secretary for Technology

National Institute of Standards and Technology

Arati Prabhakar, Director 



\section{Diagnosis of Causes of Concrete Deterioration in the MLP-7A parking Garage}

Paul E. Stutzman

James R. Clifton

Building and Fire Research Laboratory

Gaithersburg, Maryland 20899

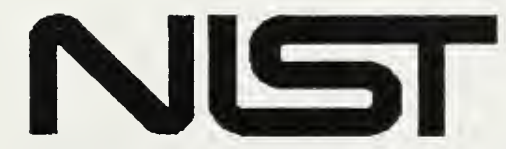

UNITED STATES DEPARTMENT OF COMMERCE

Technology Administration

National Institute of Standards and Technology 



\section{ABSTRACT}

Parking garage MLP-7A at the National Institutes of Health (NIH) is a four-level, cast-in-place concrete structure, approximately seventeen years of age which is exhibiting expansion and cracking of the parapet walls. Field inspection, petrographic analysis of concrete cores and laboratory testing are being used to identify the processes responsible for expansion and cracking of the concrete, to determine the potential for additional expansion, and to evaluate the abilities of several commercially available water repellents applied to the concrete surface to reduce water infiltration. Evidence of alkali-silica reaction was observed in core samples extracted from the parapet walls, an inside wall from the lower level, and in the upper deck as one or more of the following; crack-filling, void-filling, or aggregate-rimming reaction gel. The quantity of reaction gel is greatest in cores removed from the upper, more exposed portions of the structure. The non-uniform distribution of entrained air voids observed in some of the cores is a result of their infilling due to precipitation of calcium hydroxide, ettringite, and gypsum and may result in poor freeze-thaw resistance. An accelerated expansion test of aggregate extracted from the structure indicates that the aggregate is reactive and that there is a potential for further expansion. The performance of water repellant treatments were evaluated in field studies on the garage structure. Each repellant treatment reduced water infiltration relative to an untreated test region however, some treatments performed better in regions with visible, fine surface cracks.

KEY WORDS: alkali-silica reaction, building technology, concrete, cracking, deterioration, expansion, petrography, water repellents 


\section{Table of Contents}

\section{Page}

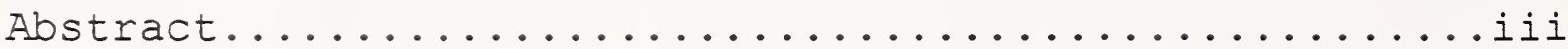

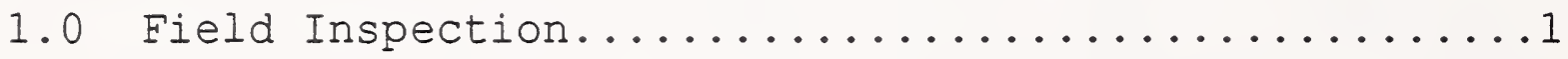

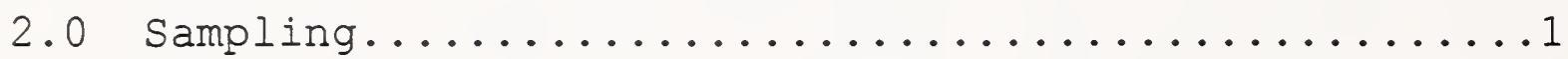

3.0 Petrography of Core Samples................

3.1 Parapet Wall Concrete.............

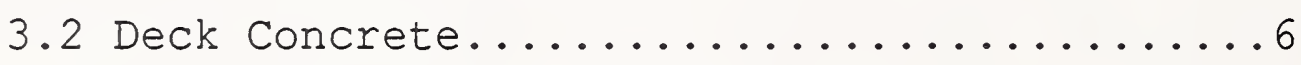

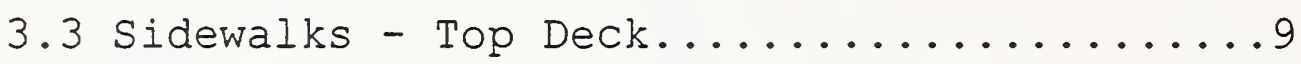

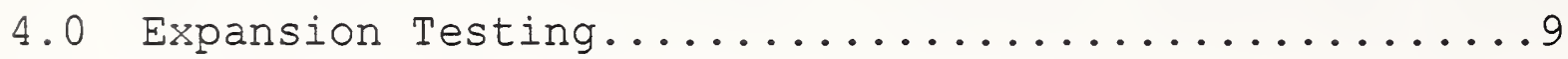

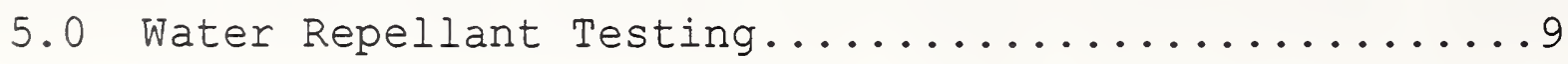

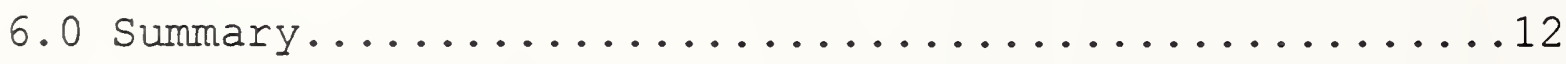

7.0 Recommendations for Further Study............12

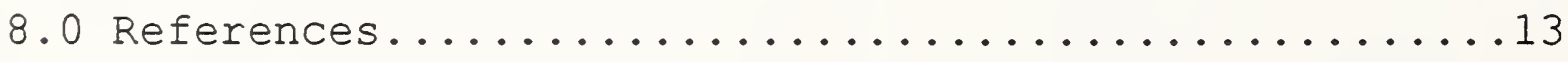


Table 1. Results of Water Absorption Tests on Horizontal $\underline{\text { Page }}$

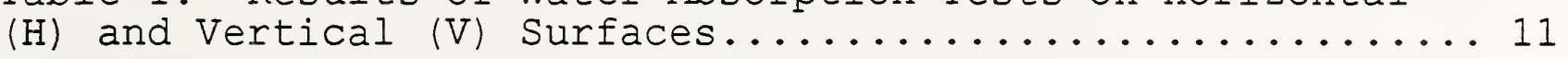

List of Figures

Figure 1. Cracking, efflorescence (on face of wall), and $\underline{\text { Page }}$ joint closure of parapet wall concrete illustrate the severity of expansion and cracking on the upper wall (a) and slightly less severe damage to the second level wall

Figure 2. Cracking of column on second level. Exposed aggregate in each image is quartz gravel similar to that used in the parapet walls and lower decks. Columns on the second level, east side, exhibited the greatest amount of cracking. Efflorescence and reaction gel

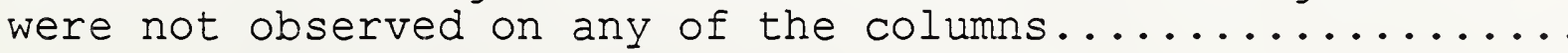

Figure 3. Full size polished slab (A) from core extracted from upper deck parapet wall. Slightly darker (tan) region across top indicates the approximate depth of carbonation. A crack of about $15 \mathrm{~mm}$ depth can be observed at the top of the core. Reaction gel can also be seen (circled) as rounded masses and at the paste/aggregate interfaces. Backscattered electron imaging ( $B$ and $C$ ) shows the aggregate (AG), paste (P), heterogeneity of entrained air void (V) distribution and some of the entrained air

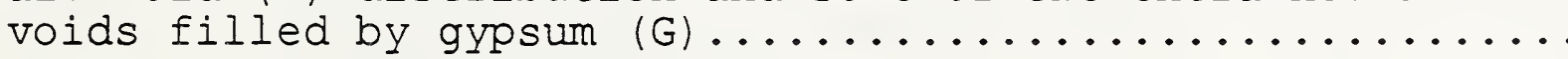

Figure 4. Full size polished slabs from (A) south parapet wall, level B-2, and of (B) the inside wall of lower-most level drilled parallel to the deck. Visible reaction gel (circled) fill voids and occurs at some paste/aggregate interfaces. Some cracking in (A) extends about $20 \mathrm{~mm}$ from the top surface and through the core depth in (B) ........7

Figure 5. Polished slab from core drilled perpendicular to the upper deck surface (A), SEM micrographs (B) illustrate the microstructure with the dark dolomitic limestone (coarse) and quartz sand (fine) aggregate. X-ray imaging (C) of potassium distribution locates chert grains containing

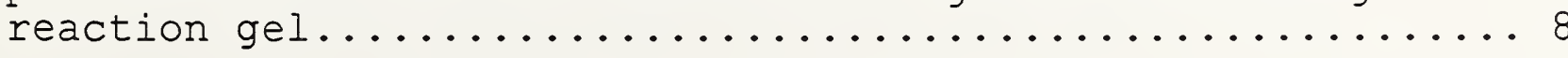

Figure 6. Results of the modified P-214 test measuring expansion due to reaction of silicious aggregate from parking garage concrete. Failure criterion of $0.1 \%$ expansion was reached after one week of testing indicating the aggregate still contains reactive silica............ 10 
Parking garage MLP-7A is a four-level, cast-in-place concrete structure approximately seventeen years of age located on the grounds of the National Institutes of Health in Bethesda Maryland. The structure is exhibiting expansion and cracking in the parapet walls. A field inspection was carried out for the purpose of examining the structure, crack patterns and locations, selecting sampling areas, obtaining cores, and determining the causes and severity of degradation. Photographs of the parking garage presented in figs. 1 and 2 show the following evidence of degradation:

- extensive map cracking of parapet walls,

- localized exudation of lime $\left(\mathrm{CaOH}_{2}\right)$ precipitating as a white efflorescence in the form of calcite $\left(\mathrm{CaCO}_{3}\right)$,

- closure of expansion joints,

- longitudinal cracking along tops of parapet walls,

- diagonal cracking in columns on the second level,

- diagonal cracking across corners of some of the decks and in lower-level interior walls,

- spalling and exposed reinforcement on lower level decks and in the southwest stairwell.

\subsection{SAMPLING}

Sampling sites were selected to obtain cores in areas exhibiting significant distress, some distress, and little or no distress. Cores were extracted from the upper deck parapet walls exhibiting significant expansion and cracking, the lower deck parapet walls which exhibited less extensive expansion and cracking, an inside wall in the lower-most level with no apparent damage, and the upper deck slab. A total of thirteen $75 \mathrm{~mm}$ diameter cores were extracted from the walls and deck: A) 4 horizontal, full-section cores from upper deck, north parapet wall; B) 1 vertical partialdepth core from upper deck; C) 4 horizontal, full-section cores from parapet wall from the south side of level B2; D) one horizontal, partial-depth core from the northwest, inside wall, and two vertical cores from the northwest corner, level B1, from a wall enclosing the lower deck ventilation shaft. Samples of spalled concrete were obtained from the deck on levels B1 and B2. 


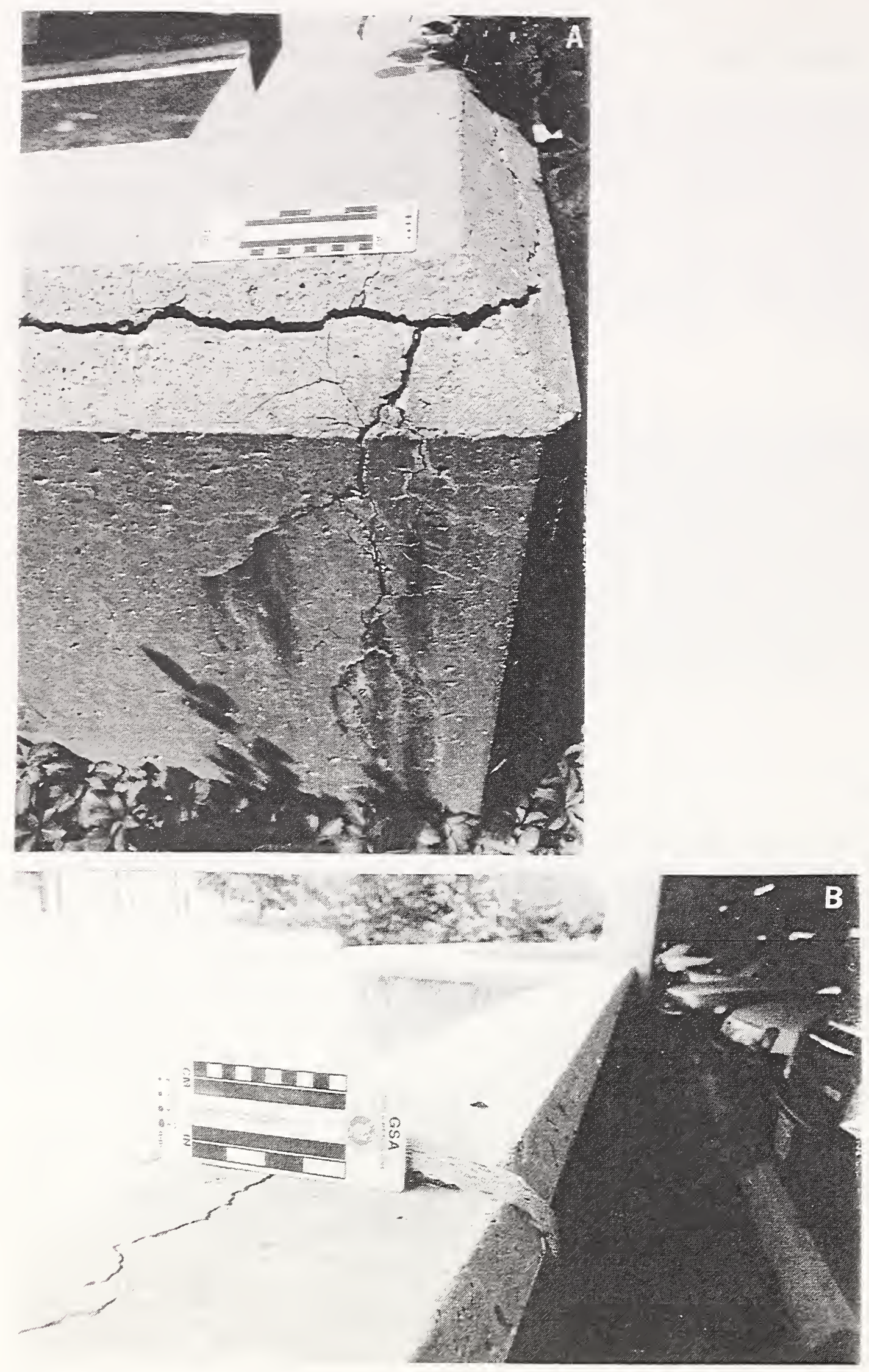

Figure 1. Cracking, efflorescence (on face of wall), and joint closure of parapet wall concrete illustrate the severity of expansion and cracking on the upper wall (a) and slightly less severe damage to the second level wall (b). 


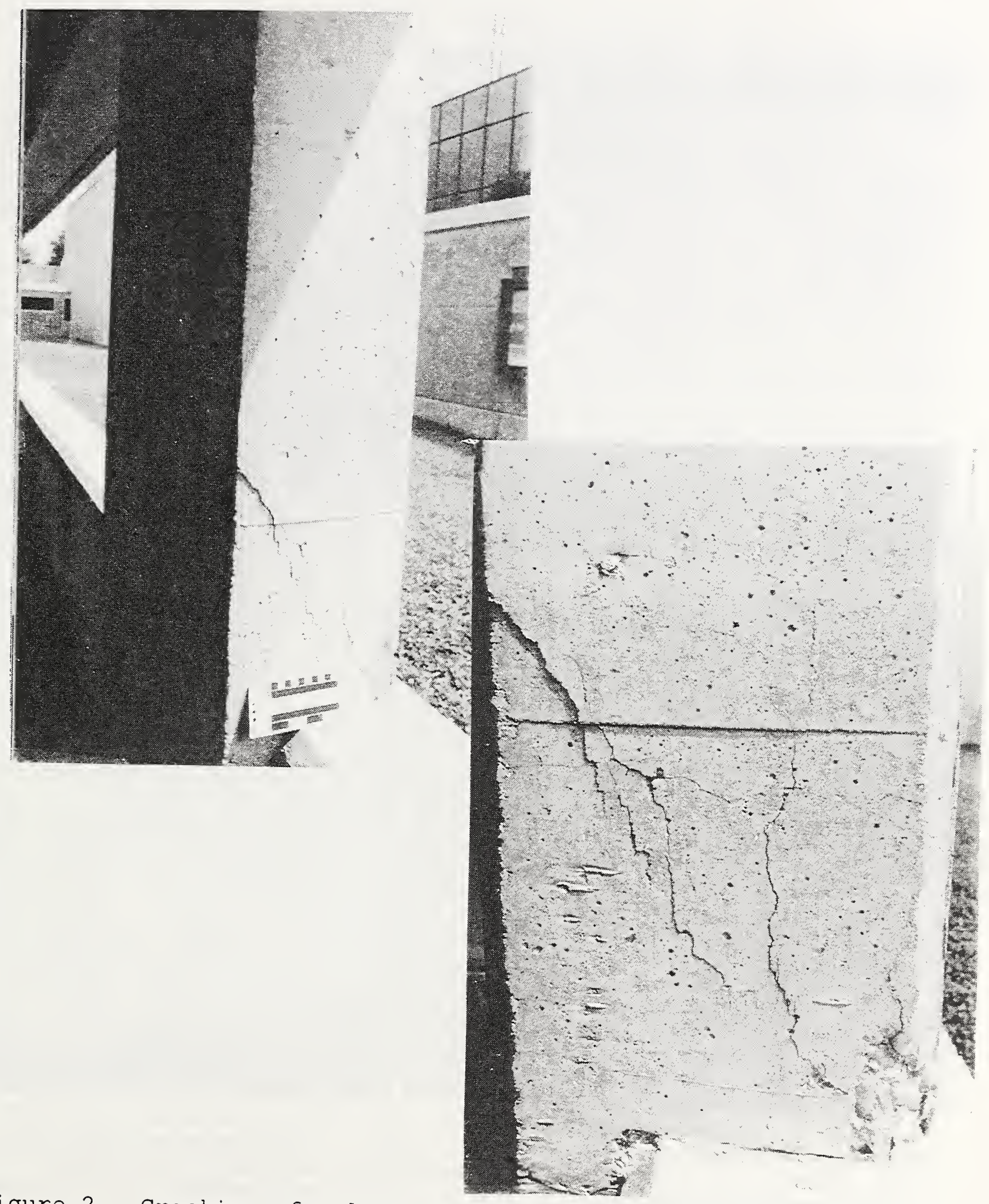

Figure 2. Cracking of column on second level. Exposed aggregate in each image is quartz gravel similar to that used in the parapet walls and lower decks. Columns on the second level, east side, exhibited the greatest amount of cracking. Efflorescence and reaction gel were not observed on any of the columns. 


\subsection{PETROGRAPHY OF CORE SAMPLES}

\subsection{Parapet Wall Concrete}

Full-section cores (horizontal) could not be extracted in one piece from the upper deck parapet wall suggesting that the prominent crack along the length of the wall extends the height of the wall. Full-section cores were successfully extracted from the parapet wall on level B-1. Polished sections of slabs sawn from these cores are presented in Figures 3-5. Aggregate in the parapet walls is a $25 \mathrm{~mm}$ maximum diameter quartz gravel coarse aggregate and quartz sand fine aggregate. Chert (very finegrained, porous quartz) is present in both the coarse and sand portions of the aggregate. The aggregate-to-paste ratio and aggregate distribution appears normal. The paste microstructure is dense and the paste appears to be well-bonded to the aggregate. The carbonation depth of about $3 \mathrm{~mm}$ is normal considering the age of the structure. All core specimens exhibit evidence of alkali-silica reaction (ASR) gel as white, soft voidfillings up to $4 \mathrm{~mm}$ in diameter, and thin $(0.25 \mathrm{~mm})$ bands of white gel rimming some aggregates. The upper deck parapet wall specimens appear to contain the greatest amounts of gel and the interior wall on the lower level exhibit the least.

Figure $3 \mathrm{~A}$ is a full size image of a polished slab from a core extracted from the upper parapet wall with the plane of the image parallel to the axis of the core. Reaction gel (circled) occurs as rounded inclusions and as rims around aggregate. A crack extending about $15 \mathrm{~mm}$ from the surface can be seen at the top of the image, while the slight discoloration of the top few millimeters marks the approximate depth of carbonation. Figs. 3B and $3 \mathrm{C}$ are higher-magnification scanning electron microscope (SEM) images of the concrete microstructure. The quartz aggregate appears as dark, angular fragments. Unhydrated cement appears as small, angular, bright grains in a light grey matrix of hardened cement paste. Air voids and cracks, filled with a resin during sample preparation, appear black. Entrained air voids $5 \mu \mathrm{m}$ to $1 \mathrm{~mm}$ in diameter appear as black circles in the SEM micrographs. The entrained air void system appears low and poorly distributed, but SEM examination shows a large number of entrained air voids filled with secondary deposits of ettringite, calcium hydroxide, and occasionally gypsum. Idorn [1] notes that this secondary ettringite and gypsum may indicate sulfate attack; but, since fig. 3c shows that some space remains in the air voids, the presence of secondary ettringite and gypsum is more likely a product of deterioration and not a cause of cracking. While an adequate volume of entrained air voids may be present for freeze-thaw resistance, the partial loss and resulting heterogeneous distribution of air voids may result in a lowered resistance to freeze-thaw damage. 


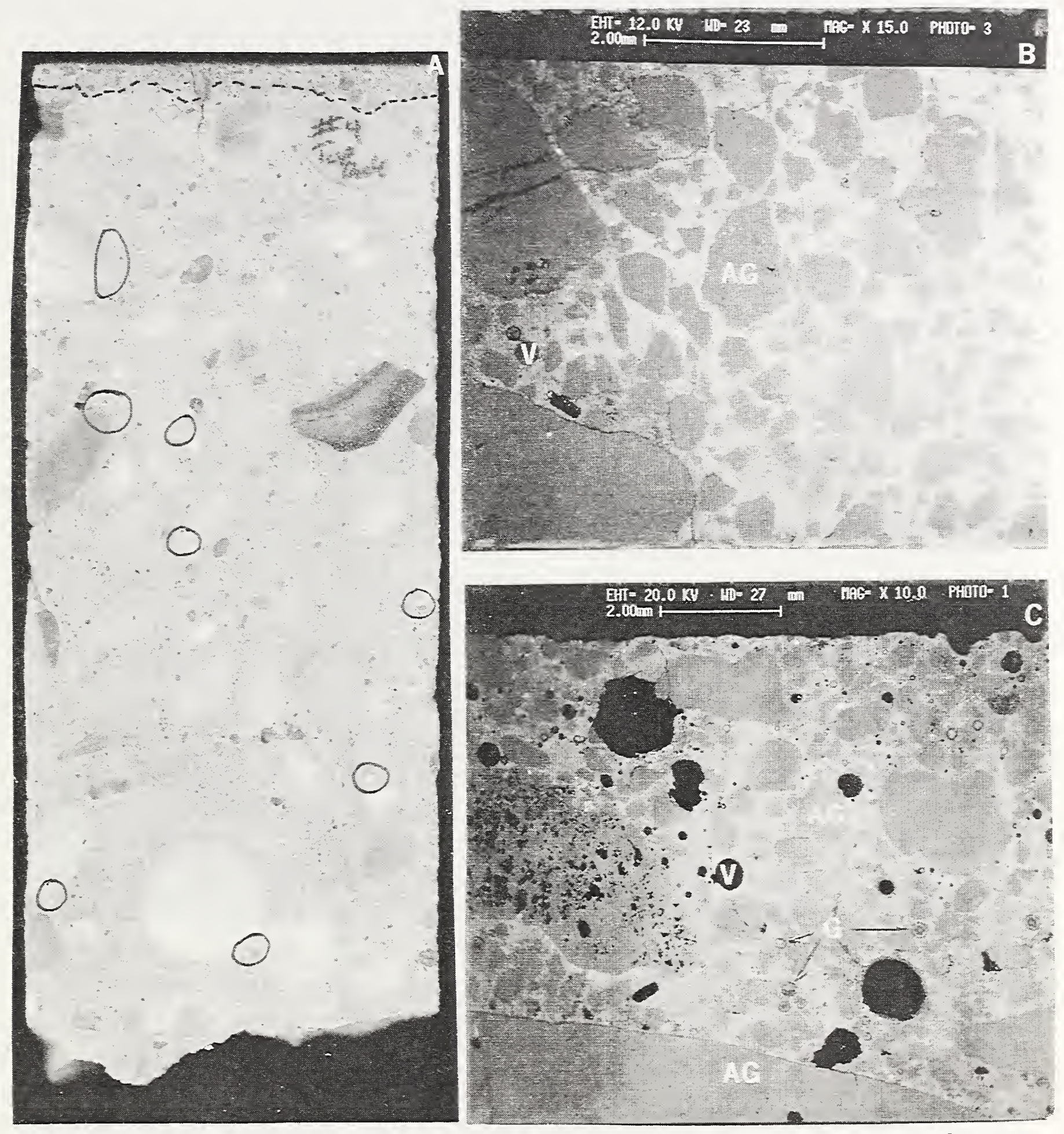

Figure 3. Full size polished slab (A) from core extracted from upper deck parapet wall. Slightly darker (tan) region across top indicates the approximate the depth of carbonation. A crack of about $15 \mathrm{~mm}$ depth can be observed at the top of the core. Reaction gel can also be seen (circled) as rounded masses and at paste/aggregate interfaces. Backscattered electron imaging ( $B$ and $C$ ) shows the aggregate (AG), paste (P), heterogeneity of entrained air void (V) distribution and some of the entrained air voids filled by ettringite, gypsum, or calcium hydroxide (G). 
Figures $4 \mathrm{~A}$ and $4 \mathrm{~B}$ are polished slabs in the plane of the axis from cores extracted from garage level B-2 and the inside wall of the lowest level. The concrete in these locations exhibited little deterioration relative to the upper parapet walls. Similarly, cracking and exudation in the core slabs is not as common as in those extracted from the upper parapet walls. However, some ASR gel is present as round inclusions and aggregate rims. These cores also exhibit a heterogeneous airvoid distribution and some cracking. Also, a low depth of carbonation is observed.

\subsection{Deck Concrete}

Figure 5 illustrates the microstructure of the core removed from the upper deck. This core was topped by a flexible membrane which is covered by about $45 \mathrm{~mm}$ of asphalt. Dampness around cracks observed on the underside of the slab indicate that water has bypassed the membrane. The upper deck and level BI deck are made with a dark carbonate coarse aggregate and a silicious fine aggregate. X-ray powder diffraction analysis identified the coarse aggregate as a dolomitic limestone composed of calcite and dolomite, and the $18 \%$ insoluble residue is composed of quartz, clays, pyrite, and feldspar. Based on composition and textures described by Walker [2], the aggregate may be potentially reactive, but reaction sites identified by SEM were not common and were only associated with the chert fraction in the sand. No reactions were observed in the carbonate aggregate. Paste and aggregate proportions appear normal and the aggregate is well distributed. The paste is hard, appears dense, bonds well to the aggregate and appears to be carbonated to about $2 \mathrm{~mm}$. The entrained air void system appears to be more uniformly distributed than in the parapet wall concretes. No secondary deposits were observed to fill the air voids. Over-finishing the surface has resulted in the loss of entrained air and preferred orientation of the aggregate in the top-most centimeter. If the membrane is damaged, allowing the concrete to become saturated, the loss of entrained air may result in scaling of the top-most layer of concrete by frost attack.

Location of reaction gel and identification of the reactive aggregate are facilitated by SEM imaging (Fig. 5). A SEM backscattered electron image shows a rimmed, mottled, porous chert grain (5 C) while the X-ray image indicates the presence of silicon and potassium. Alkali-silica reaction activity appears to be limited to chert grains in the sand fraction of this concrete.

Concrete in deck B-2 and the other lower decks contains the same quartz gravel used in the parapet walls and columns. These decks were not cored and the grab samples, less than $20 \mathrm{~mm}$ thick, do not represent a cross-section of the slab concrete. The paste microstructure appears similar to that observed in the parapet walls with a dense paste, low depth (2-3 mm) of carbonation, well distributed aggregate, and non-uniform spatial distribution of 

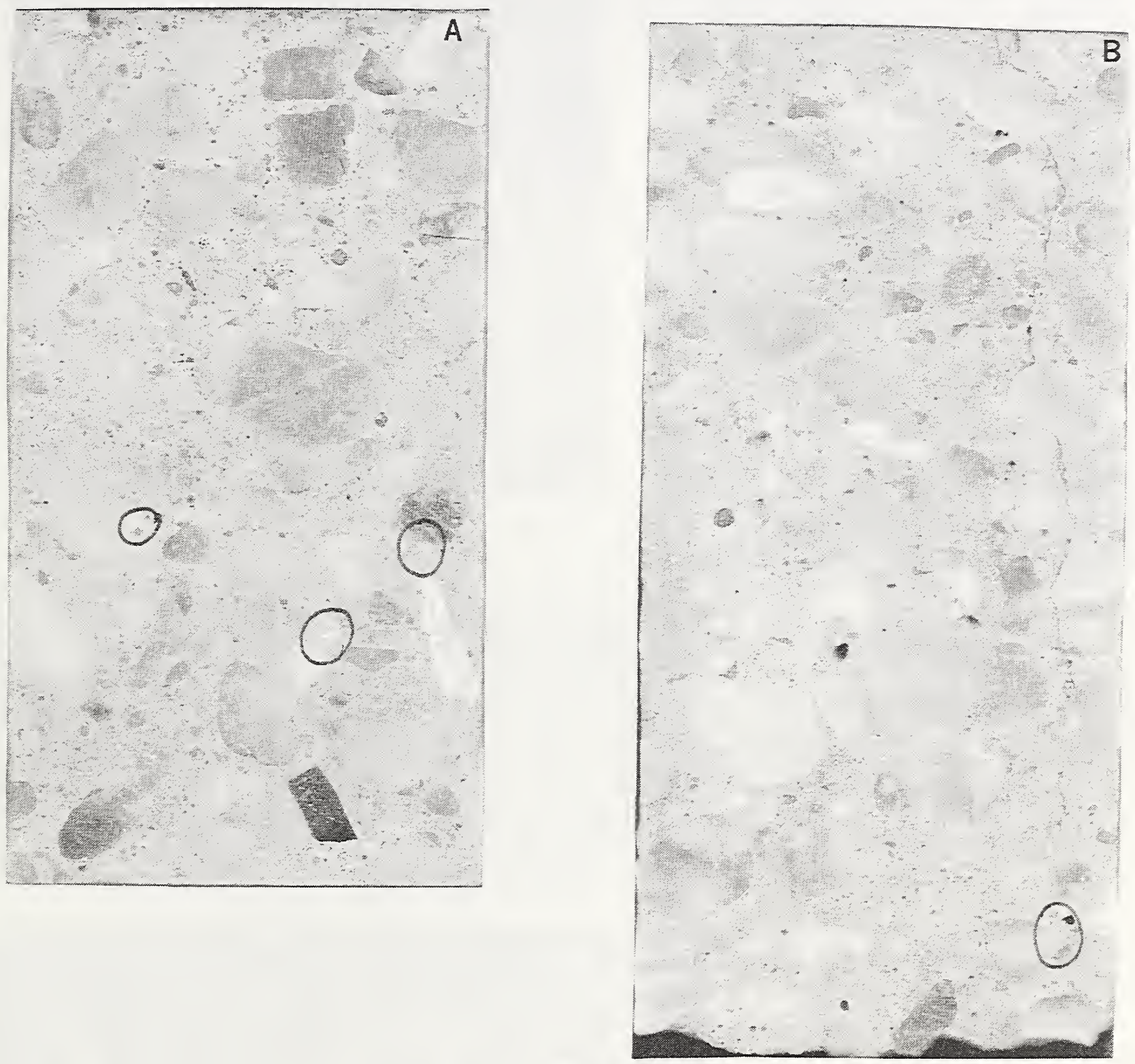

Figure 4. Full size polished slabs from (A) south parapet wall, level B-2, and of (B) the inside wall of lower-most level drilled parallel to the deck. Visible reaction gel (circled) fill voids and occurs at some paste/aggregate interfaces. Some cracking in (A) extends about $20 \mathrm{~mm}$ from the top surface and through the core depth in (B). 

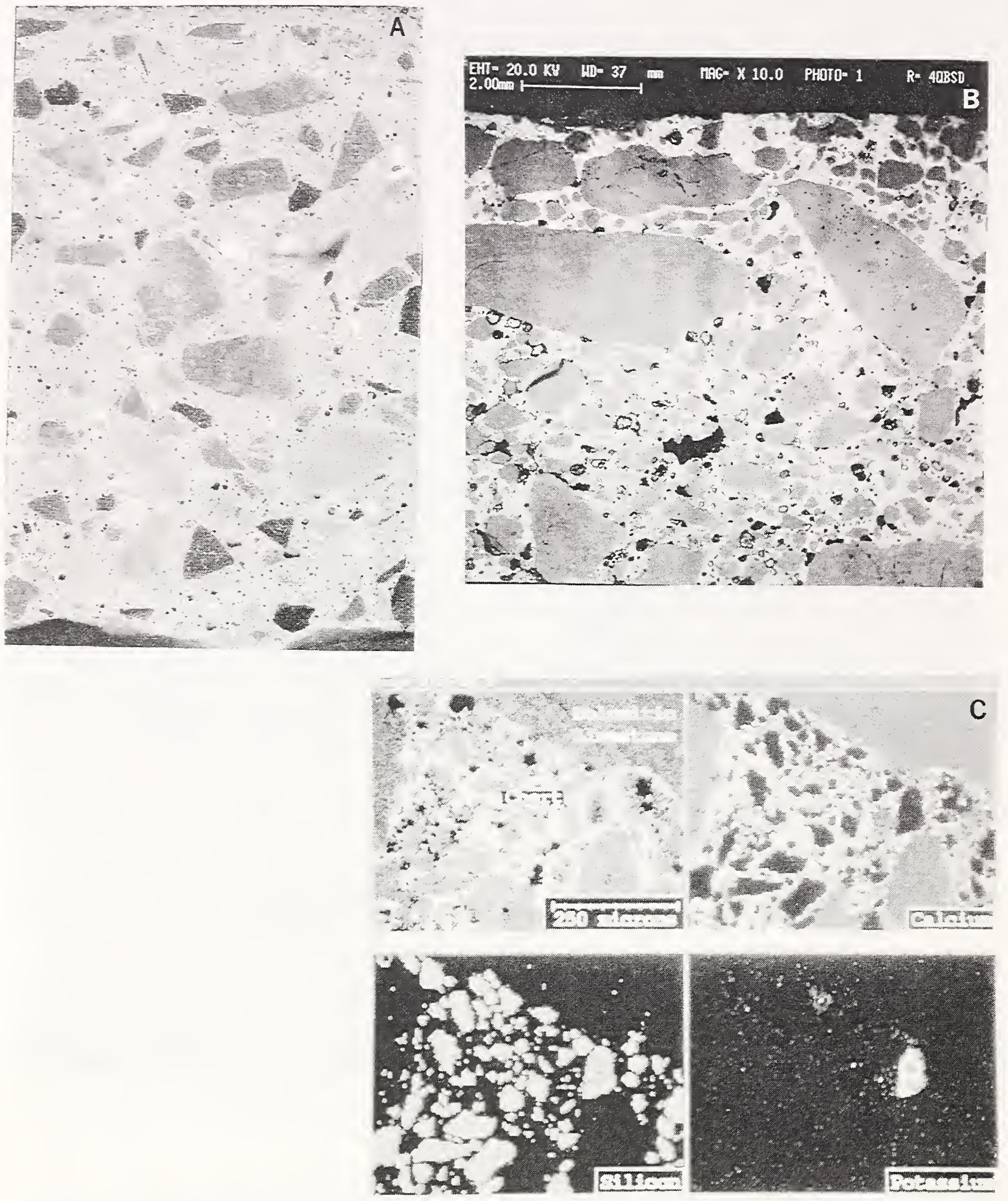

Figure 5. Polished core slab from core drilled perpendicular to the upper deck surface (A), SEM micrographs (B) illustrate the microstructure with the dark dolomitic limestone (coarse) and quartz sand (fine) aggregate. X-ray imaging (C) of potassium distribution locates chert grains (silicon image, porous grains) containing reaction gel. 
entrained air voids. Evidence of ASR activity was not seen in these samples. Beneath the spalled sections of concrete from each deck sampled was corroded reinforcement. Chloride was detected by $\mathrm{X}$-ray probe analysis in the paste near fractures leading from corroded reinforcement. Concrete thickness over reinforcement was variable, with some cover being only $10 \mathrm{~mm}$ thick. ACI 201.2R-19, Guide to Durable Concrete [4] recommends $38 \mathrm{~mm}$ to $50 \mathrm{~mm}$ of concrete cover in moderate corrosion environments, such as a bridge where salt is applied for ice control.

\subsection{Sidewalks - Top Deck}

The sidewalks do not show signs of expansion or distress and appear to be made with the same carbonate coarse aggregate as the upper level deck and level BI deck. However, one portion of the sidewalk in the southeast corner of the upper deck does show map cracking. Inspection of this region reveals the use of the quartz gravel as the coarse aggregate.

\subsection{EXPANSION TESTING}

Expansion testing to examine the potential for continued reactivity of the aggregate utilized a modified version of the ASTM P 214 test [3]. An aggregate sample from the structure was extracted from the cores by crushing and sieving. The aggregate was crushed, sieved, graded, and cast in mortars. The mortars were cured for 24 hours, and placed in a $1 \mathrm{~N} \mathrm{NaOH}$ solution at $80^{\circ} \mathrm{C}$ while measuring length change. The elevated temperature and alkali content of the solution is intended to force potentially reactive aggregates to expand. A length increase of greater than $0.1 \%$ within 14 days indicates the aggregate is still reactive and further expansion could be anticipated. The results of this test indicated that the aggregate is still reactive and further expansion may take place. Expansion measurements after 140 days averaged $0.61 \%$, continuing the trend presented in Figure 6 .

\subsection{WATER REPELLENT TESTING}

According to the ACI Guide to Durable Concrete [4], there are no proven treatments for the preservation of existing concrete that contains reactive aggregate, high alkali levels, and moisture. ACI 201.2 states that water or moisture is a component of these reactions and the effects of freeze-thaw after alkali-aggregate expansion is more severe, and therefore concludes that any means of decreasing the exposure of concrete susceptible to alkaliaggregate or freeze-thaw degradation may extend the useful life of a concrete structure. Water repellant treatments applied to concrete are designed to minimize the ingress of water. However, the effectiveness of water repellents in the minimization of expansion due to alkali-aggregate reactions or freeze-thaw action has not been demonstrated. Stark [5], states that expansion due to alkali-aggregate reactions can develop if the relative humidity of the concrete is greater than 85 percent, referenced to $21^{\circ}$ to $23^{\circ} \mathrm{C}$. 


\section{Mortar Bar Expansion}

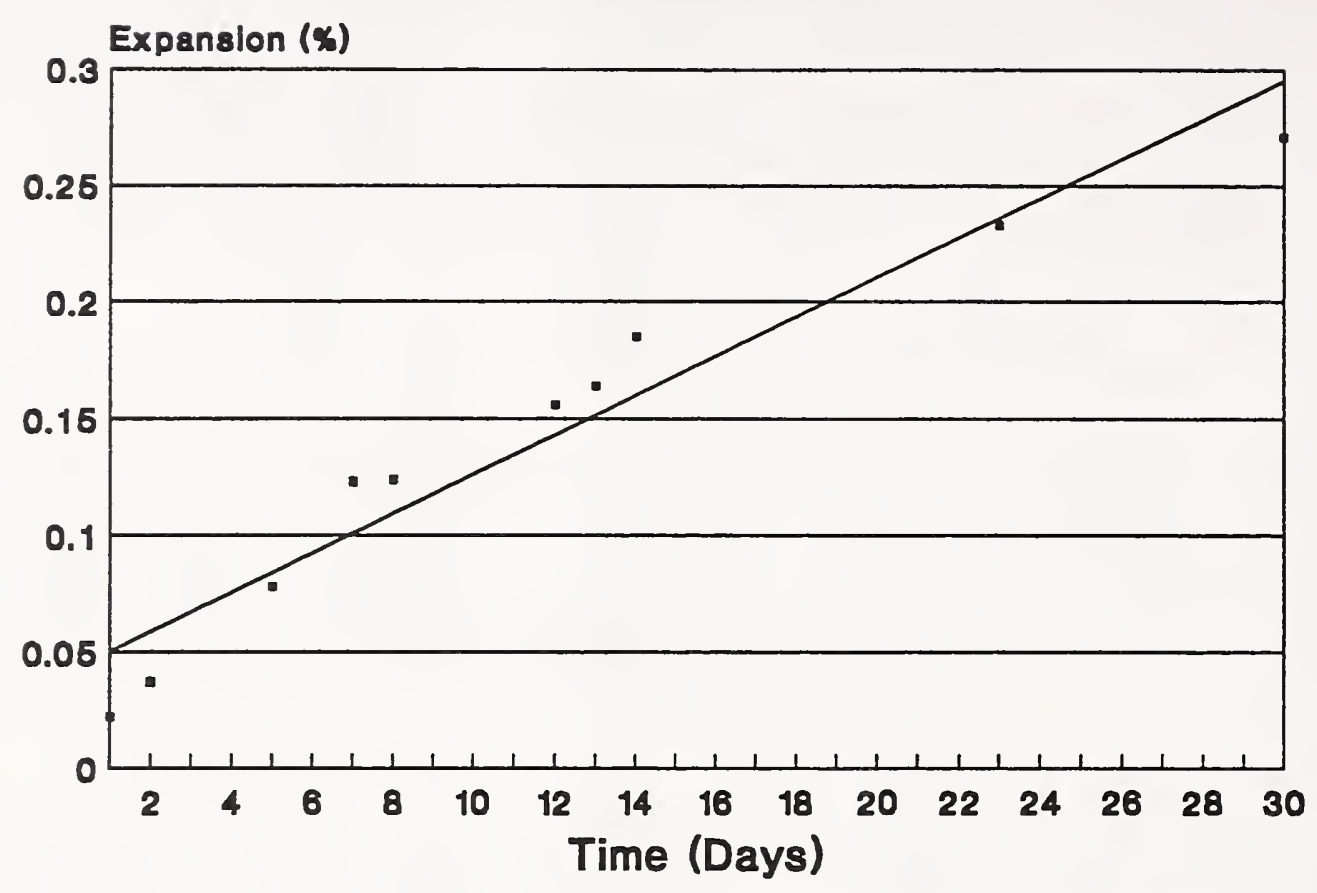

Figure 6. Results of the modified P 214 test measuring expansion due to reaction of silicious aggregate from parking garage concrete. Failure criterion of $0.1 \%$ expansion was reached after one week of testing indicating the aggregate still contains reactive silica.

Litvan [6] noted that while water repellent sealers decreased the water uptake in laboratory mortar specimens, the freeze-thaw durability of the mortars was not improved and, in many cases, was decreased. This result was attributed to restrictions on water movement near the surface of the mortars.

Water repellent treatment tests of a penetrating silane, siloxane, and a flexible acrylic surface coating show a significant reduction in water absorption. Water absorption was measured using a RILEM tube [7], a device consisting of a waterfilled graduated cylinder attached to the concrete. The water loss measured after 24 hours gives relative information on the absorption characteristics of the untreated concrete and the effectiveness of the different inhibitor types. It should be noted that, according to the manufacturers, these treatments provide water barriers while allowing passage of water vapor. Trapping of moisture in the concrete by water and vapor barriers may result in spalling of the surface layers by freeze-thaw cycling. Except for one repellant, a tinted surface coating, the sealers did not alter the color of the concrete. Any lighter coloring is due to wire brushing the dirt off the concrete prior to treatment. Application was carried out following 
manufacturers' recommendations. After drying and curing, water was found to bead on each treated area. Both horizontal and vertical surfaces were treated.

Four commercial water repellents representing different formulations were selected for evaluation:

1. a colorless poly-siloxane resin,

2. a flexible, crack-bridging, water-based acrylic,

3. water-based silane and siloxane,

4. siloxane.

Water absorption tests were done using RILEM test method II.4, Measurement of Water Absorption Under Low Pressure [7]. A tube is attached to the surface with silicone caulk and is filled with water. According to the procedure, the height of the water in the tube (approx. $10 \mathrm{~cm}$ ) created a pressure of $961.38 \mathrm{~Pa}$, corresponding to a dynamic wind pressure of $142.6 \mathrm{~km} / \mathrm{hr}$. Results of the water absorption tests are presented in Table 1. Sealants \#1 and \#2 appear to give the best results for both the vertical and horizontal surfaces. The discrepancy between the vertical and horizontal sealant \#4 data may be due to fine cracks in the vertical test site.

Table 1. Results of Water Absorption Tests on Horizontal (H) and Vertical (V) Surfaces

\begin{tabular}{llc}
\hline SITE & \multicolumn{1}{c}{ PRODUCT } & ABSORPTION \\
\hline $1 \mathrm{H}$ & untreated, cracked & 68 \\
$2 \mathrm{H}$ & $\# 2$, water-based acrylic & 2 \\
$3 \mathrm{H}$ & $\# 1$, poly-siloxane resin & 3 \\
$4 \mathrm{H}$ & $\# 3$, silane and siloxane & 5 \\
$5 \mathrm{H}$ & $\# 4$, siloxane & 21 \\
$6 \mathrm{H}$ & untreated & 14 \\
$7 \mathrm{H}$ & untreated, cracked & $>110$ \\
& & \\
$8 \mathrm{~V}$ Wa11 & untreated & 4 \\
$10 \mathrm{~V}$ & untreated & 6 \\
$11 \mathrm{~V}$ & $\# 2$, water-based acrylic & 1 \\
$12 \mathrm{~V}$ & $\# 1$, poly-siloxane resin & 0.5 \\
$13 \mathrm{~V}$ & $\# 1$, poly-siloxane resin, cracked surface \\
$13 \mathrm{AV}$ & $\# 3$, silane and siloxane, cracked surface & $>110$ \\
$14 \mathrm{~V}$ & $\# 3$, silane and siloxane & 27 \\
$15 \mathrm{~V}$ & $\# 4$, siloxane & 4 \\
$16 \mathrm{~V}$ & $\# 4$, siloxane, cracked surface & 3.5 \\
& & \\
\hline
\end{tabular}




\section{0 summary}

A field and laboratory examination of the MLP-7A parking garage at the national Institutes of Health indicates that alkali-silica reaction is occurring in the concrete of the structure. Evidence of alkali-silica reaction as observed in cores extracted from the garage include reaction gel filling cracks, gel-filled voids, and gel-rimmed silicious aggregate. Secondary deposition of ettringite and gypsum has reduced the volume of entrained air voids and, potentially, the resistance of the concrete to freezethaw degradation. Severity of the cracking and presence of reaction gel are greatest in concrete extracted from the upper parapet walls. The upper deck slab shows some reaction due to chert in the sand fraction. The coarse aggregate of the upper deck slab, a dolomitic limestone, appears to be unaffected. Accelerated expansion tests of the silicious coarse aggregate extracted from the parapet walls indicate that the aggregate is still reactive and that the reaction and expansion may continue. Tests of water repellent surface treatments indicate that they are effective in minimizing the infiltration of liquid water however, studies on the effectiveness of sealers question the value in their application for the reduction of damage due to alkali-aggregate or freeze-thaw expansion. Sealing of the longitudinal cracks in the parapet walls followed by application of a water repellent sealer to the horizontal surfaces of the parapet walls should minimize the ingress of water while allowing for transport of water out of the concrete.

\subsection{Recommendations for Further Study}

It is recommended that a long-term monitoring plan be set up to document the condition of the structure and changes, if any, over time. This documentation will aid the evaluation of the condition and in formulating repair and rehabilitation plans throughout its remaining service life. The monitoring plan should include a detailed crack and delamination mapping and photographic record of each column, slab, wall, and parapet wall; in addition, crack displacement monitor gauges should be installed at selected points. 
8.0 References

1 Idorn, G.M., Durability of Structures in Denmark, A Study of Field Behaviour and Microscopic Features, Technical University of Denmark, Copenhagen, 1967, 208 pp.

2 Walker, H.N., "Chemical Reactions of Carbonate Aggregates in Cement Paste", in Significance of Tests and Properties of Concrete and Concrete-Making Materials, ASTM STP 169B, American Society for Testing and Materials, Philadelphia, PA, pp. $722-743,1978$.

3 ASTM P-214, Proposed Test Method for Accelerated Detection of Potentially Deleterious Expansion of Mortar Bars Due to Alkali-Silica Reaction, American Society for Testing and Materials, Philadelphia, PA.

4 ACI 201.2R-77, "Guide to Durable Concrete," ACI Manual of Concrete Practice, Part 1, American Concrete Institute, Detroit, 1990.

5 Stark, D., "Investigation of Alkali-Silica Reactivity in Four Dams in the Southeastern United States", U.S.

Department of the Interior Bureau of Reclamation Report RECERC-89-4, 1989, 42 pp.

6 Litvan, G.G., "The Effect of Sealers on the Freeze-Thaw Resistance of Mortar", Cement and Concrete Research, Vol. 22, pp. 1141-1147, 1992.

7 Measurement of Water Absorption Under low pressure, RILEM Test Method No. II.4, ProSoCo, Inc. Technical Service Technote, Prosoco, Inc, Kansas City, KS. 

